\title{
ETNOBOTÂNICA DE PLANTAS RITUALÍSTICAS NA PRÁTICA RELIGIOSA DE MATRIZ AFRICANA NO MUNICÍPIO DE ITUIUTABA, MINAS GERAIS, BRASIL
}

\author{
ETHNOBOTANY OF RITUALISTIC PLANTS IN THE RELIGIOUS PRACTICE OF \\ AFRICAN MATRIX IN THE CITY OF ITUIUTABA, MINAS GERAIS, BRAZIL
}

${ }^{1}$ Kenneri Cezarini Hernandes ALVES; ${ }^{2}$ Juliana Aparecida POVH; ${ }^{3}$ Anderson Pereira PORTUGUEZ

${ }^{1}$ Graduação em Ciências Biológicas, ${ }^{1}{ }^{2}$ Universidade Federal de Uberlândia. Instituto de Ciências Exatas e Naturais do Pontal, Ituiutaba, MG, Brasil. Laboratório de Botânica e Ecologia no Domínio Cerrado (LABEC), Campus Pontal, Ituiutaba, MG, Brasil. ${ }^{1}$ kenneri.hernandes@gmail.com 2Japovh.ufu.br ${ }^{3}$ Universidade Federal de Uberlândia e Instituto de Ciências Humanas do Pontal - (ICHPO) . .3portuguez.andersonpereira@gmail.com

\section{RESUMO}

Submitted: 11/06/2019; Accepted: 19/08/2019

As plantas, no universo das religiões de influência africana, apresentam grande valor por serem utilizadas para propósitos ritualísticos e de rotina pelas comunidades dos terreiros. Neste sentido, este estudo foi realizado com o objetivo de compreender e analisar a etnobotânica nas religiões de Umbanda e Candomblé com fins medicinais, indicadas pelo babalorixá e citadas nos formulários respondidos por 20 participantes. Foram realizadas visitas para coleta de dados a fim de preparar um catálogo com os seguintes itens: nome científico, família botânica, nome popular, uso religioso e terapêutico, seguida de imagens de cada espécie presente no quintal do terreiro ILé Àse Tobi Babá Olorigbin, localizado na cidade de Ituiutaba, Minas Gerais. Os resultados possibilitaram compreensão dos benefícios que os rituais e a utilização de plantas promovem, melhorando qualidade de vida e levando bem-estar aos praticantes da religião. Por fim, este estudo contribuiu para registrar os conhecimentos e cultura da religião afro-brasileira e desmistificar o preconceito sobre os terreiros de Umbanda e Candomblé.

Palavras-chave: Candomblé; plantas medicinais; rituais; Umbanda.

\begin{abstract}
Plants are of great value in the religious universe of African-influence religions as they have been used for ritualistic and routine purposes by terreiros communities. In this sense, this study was accomplished with the aim of understanding and analyzing the ethnobotany of medicinal plants in Umbanda and Candomblé religions, which are indicated by the babalorisha as well as by some participants by means of a semi-structured interview. We carried out technical visits for data collection in order to prepare a catalog with the following items: scientific name, botanical family, vernacular name, religious and therapeutic uses, followed by images from each species present in the backyard of the terreiro ILé Àse Tobi Babá Olorigbin, which is located in the city of Ituiutaba, Minas Gerais. The results have enabled the understanding from benefits that the rituals and the use of plants have promoted in the quality of life and well-being of the religion practitioners. Finally, this study contributed to register the knowledge and culture of Afro-Brazilian religion and to demystify the preconception about the terreiros of Umbanda and Candomblé.
\end{abstract}

Keywords: Candomblé; medicinals plants; rituals; Umbanda.

\section{INTRODUÇÃO}

Na colonização do Brasil, os escravos foram classificados de acordo com a região de onde embarcaram na África e as etnias predominantes foram: Bantos (Congo, Angola, Moçambique e outros), Jejes (Benin, Togo, Gana e Nigéria) e Nago-Yorubás (Benin, Nigéria, Ketu e outros) (Ferreira, 2008). Os africanos, logo quando chegaram ao Brasil, após terem sobrevivido às precárias condições da viagem nos porões dos navios negreiros, em meados do século XVI até metade do século XIX, foram escravizados e trabalhavam principalmente na produção açucareira, ocupando toda costa litorânea e interior do país, principalmente Minas Gerais e Goiás. Assim, houve grande influência africana na cultura brasileira, principalmente na música, língua, culinária e religião (Cascudo, 1978).

As religiões de matriz africana foram introduzidas durante o processo de colonização do Brasil, pois os escravizados trouxeram seus ensinamentos e se mantiveram fiéis a seus costumes e crenças. 
Entretanto, com o desenvolvimento da Europa e necessidade de explorar novas regiões, associado à chegada dos portugueses ao Brasil, houve outras influências que contribuíram para a diversidade da cultura brasileira, resultando em divergências de opiniões devido às crenças dos indígenas, africanos e portugueses (Silva, 2005).

Os europeus exigiam que os escravos fossem batizados e os forçaram a seguir os ensinamentos do catolicismo, eram proibidos de praticar algum tipo de religião que não fosse a Católica. Assim, os indígenas e africanos foram catolizados e serviam a doutrina dos brancos, porém isto não fez com que perdessem a fé em suas entidades. Após a escravidão, a partir do enraizamento cultural de africanos escravizados e saberes dos indígenas, foram criadas as religiões afro-brasileiras da Umbanda e Candomblé (Silva, 2005).

A cultura é formada pelo modo de vida de um grupo social, incluindo formas de influenciar ou sendo influenciado por doutrinas em relação a determinado espaço social. Este fenômeno ocorreu com as religiões de matrizes africanas e indígenas, onde os europeus determinaram que os princípios do catolicismo fossem considerados mais importantes ou superiores em relação às outras, promovendo assim o etnocentrismo. Esta intolerância às outras religiões resultou na depreciação da cultura de outras etnias, ocasionando o preconceito às religiões afro-brasileiras, que é observado até os dias atuais, em especial aos terreiros (Portuguez, 2015).

Há milênios o ser humano utiliza plantas e praticam certos rituais como forma de cura para diversas enfermidades, sejam estas físicas ou psicológicas, obtendo técnicas para limpezas espirituais, na busca pelo bem-estar e equilíbrio do corpo físico e energético. Atualmente, diversas plantas são utilizadas em rituais de religiões de matriz africana, que promovem a aproximação do mundo espiritual por meio de oferendas e ativação das plantas para fins curativos. Entretanto, as religiões de matriz africana são discriminadas aos olhos da comunidade devido aos prejulgamentos criados por outras religiões; assim, os saberes religiosos de matriz africana se tornaram algo exclusivo dos terreiros.

As espécies vegetais utilizadas pelas religiões de matriz africana no Brasil tiveram forte influência indígena e europeia. Os africanos foram se fixando em diferentes regiões do país e foram incorporando outras espécies, que encontravam disponíveis, aos seus costumes, justificando o uso de plantas nativas brasileiras nos rituais (Camargo, 1988). Tais plantas representam várias simbologias, apresentando um caráter farmacobotânico empírico para cura de enfermidades ou problemas espirituais. Assim, o presente trabalho teve como objetivo catalogar as espécies utilizadas em práticas ritualísticas no terreiro brasileiro do ramo Ketu originado da etnia Yorubá, localizado no município de Ituiutaba, Minas Gerais. Além disso, registra os nomes populares atribuídos às plantas pelo babalorixá e relata a atuação da religião na promoção de cura e bem-estar.

\section{MATERIAL E MÉTODOS \\ Área de estudo}

Este estudo foi realizado no município de Ituiutaba, localizado no oeste do Estado de Minas Gerais (Figura 1). Ituiutaba possui uma área de $2.694 \mathrm{~km}^{2}$ tendo como vegetação típica do Cerrado (Prefeitura Municipal de Ituiutaba, 2018). O município possui atualmente 104,067 habitantes, dentre os quais 93.125 são residentes na área urbana e 4.046 na área rural, com uma densidade demográfica igual a 37,40 hab/km² (IBGE, 2010). A população economicamente ativa é de 49.862 habitantes (Prefeitura Municipal de Ituiutaba, 2018).

O terreiro ILé Àse Tobi Babá Olorigbin foi o primeiro a se regularizar na Prefeitura Municipal de Ituiutaba e também na Federação Espírita, Umbandista e Candomblé de Minas Gerais, considerado a construção pioneira no loteamento Cidade Jardim, situado no terreno de número 399 da Rua das Orquídeas, bairro Residencial Cidade Jardim, na região Sul do município, próximo dos bairros Pirapitinga, Camilo Chaves e Lagoa Azul II (Portuguez, 2016).

O trabalho foi submetido ao Conselho de Ética em Pesquisa com Seres Humanos (CEP) da Universidade Federal de Uberlândia e, após aprovação, sobre o registro 078401/2018, a equipe executora deu início ao seu desenvolvimento. 


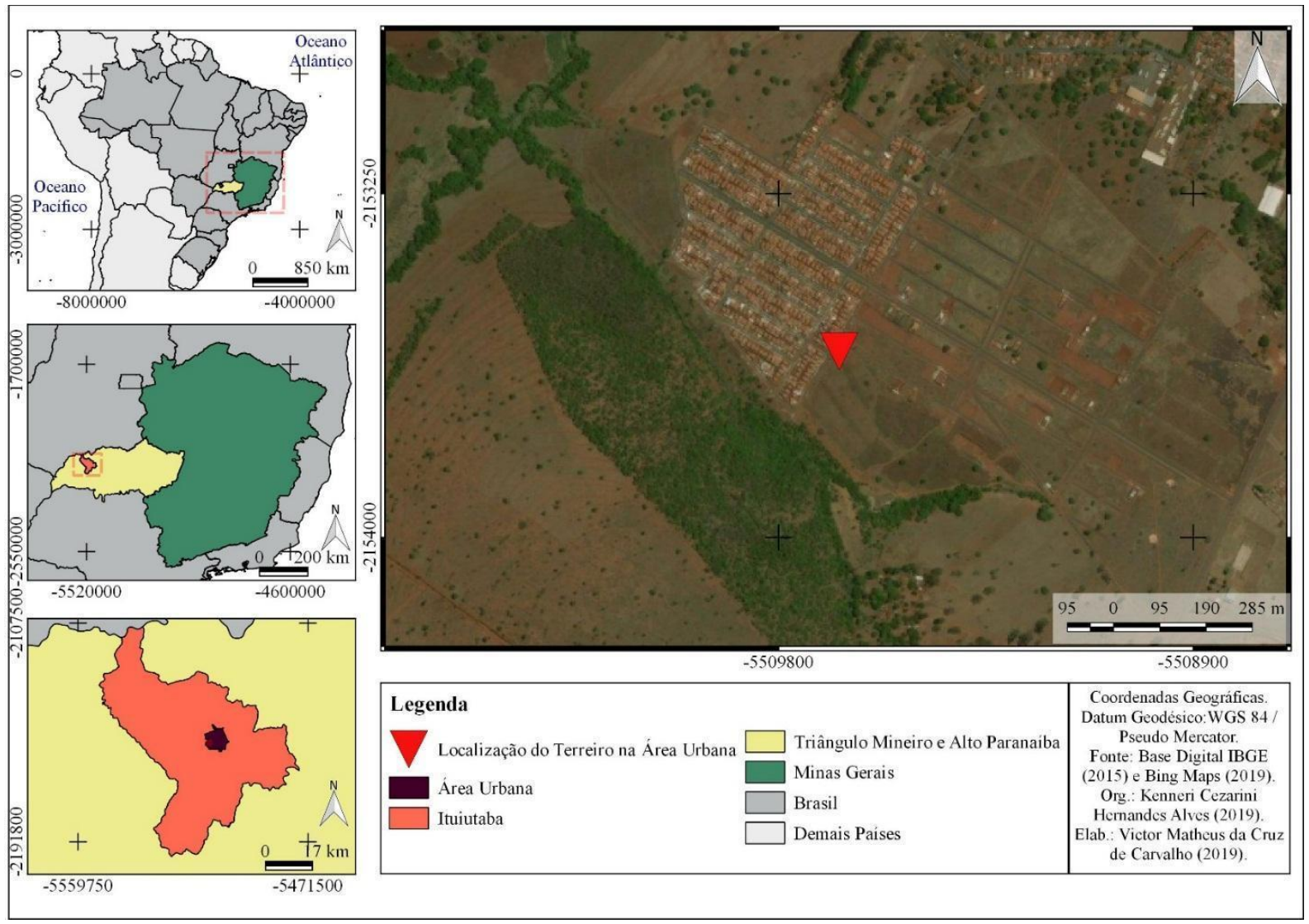

Figura 1. Mapa com a localização do terreiro Axé Olorigbin, localizado no município de Ituiutaba, Minas Gerais.

\section{Coleta de dados}

O trabalho foi desenvolvido em três etapas: visita prévia, aplicação de um formulário e coleta. A visita prévia foi realizada para identificar as ervas ocorrentes no quintal do terreiro, além de conhecer o local que seria feita a aplicação dos formulários e alinhar com o babalorixá os dias e próximas etapas do projeto. A aplicação do formulário foi realizada aos sábados, dias das giras no terreiro. Ao todo, 20 participantes responderam. Após a aplicação do formulário e coleta de dados, todas as espécies citadas pelos participantes foram identificadas e catalogadas, contribuindo para a criação de um catálogo das espécies utilizadas nos rituais.

As coletas dos dados ocorreram entre os meses de novembro e dezembro de 2018. A equipe executora realizou a primeira visita no templo em novembro para explicar os objetivos da pesquisa ao babalorixá e participantes. A primeira abordagem foi realizada diretamente aos frequentadores do templo a fim de promover recrutamento dos participantes; para isso, eles foram esclarecidos e convidados a participarem da pesquisa, e apenas os que concordaram e assinaram o Termo de Consentimento Livre e Esclarecido (TCLE) responderam ao formulário semiestruturado, o qual teve como objetivo verificar os conhecimentos que os participantes possuíam em relação à utilização de plantas na religião.

A aplicação do formulário semiestruturado possibilitou o diálogo com o babalorixá sobre formas de uso das plantas e relatos dos benefícios que a religião trouxe aos frequentadores. Os participantes não foram identificados e as questões buscaram registrar algumas informações, tais como idade e sexo dos entrevistados, dados sobre as plantas utilizadas, modo de uso, finalidade e capacidade de curar enfermidades. Estes parâmetros utilizados seguem o modelo descrito por Negrelle e Fornazzari (2007).

A coleta do material botânico, realizada após análise dos dados, foi guiada pelo babalorixá nos jardins do terreiro, e apenas as plantas mais citadas pelos participantes foram coletadas. O material foi herborizado e as exsicatas depositadas na coleção de plantas medicinais do Herbário de Uberlândia, HUFU (Holmgren et al., 1990). A identificação das espécies foi realizada de acordo com o sistema APG IV (2016).

Para determinar o fim da coleta de dados foi utilizada a curva de acumulação de espécies, curva do coletor, que permitiu avaliar o quanto o estudo se aproximou de capturar todas as espécies do local. 
Quando a curva estabiliza, ou seja, nenhuma nova espécie é adicionada, significa que a riqueza total foi obtida. A partir disso, novas amostragens não foram necessárias (Schilling; Ferreira 2008).

Com as informações obtidas, foi elaborada uma lista de espécies catalogadas em ordem alfabética das famílias botânicas, seguidas pelos nomes científicos, nomes populares e usos na religião. Além disso, houve um retorno para a comunidade estudada através da doação de uma cartilha com todas as plantas citadas pelos entrevistados e as principais informações sobre identificação e propriedades medicinais das espécies utilizadas na religião.

\section{RESULTADOS E DISCUSSÃO}

Foram catalogadas 53 espécies vegetais distribuídas em 30 famílias. Para cada espécie citada foram registrados a indicação de uso, nome científico, família botânica, nome religioso, nome popular e uso religioso (Anexo 1). Foram entrevistados 20 participantes que frequentam os ritos e realizados vários diálogos com o babalorixá, sendo possível estabelecer expressiva representatividade das espécies, cerca de 95\%, que são utilizadas nos rituais de Umbanda e Candomblé presentes no terreiro Axé Olorigbin.

A família botânica com maior citação de espécies foi Asparagaceae, com cinco espécies citadas (Figura 2). Estudos realizados por Pires et al. (2009) em terreiros de Candomblé em municípios da Bahia relatam o uso de 73 espécies de plantas, sendo a família Asteraceae majoritária em citações de espécies.

O levantamento das espécies botânicas descritas contribuiu para compreensão da importância do nome científico das espécies, pois existe diferença nos nomes populares em diferentes regiões e na religião. Além disso, os nomes escolhidos para as plantas, na religião, têm relação com sua ação medicinal. Uma delas é a tira-teima ou vence-demanda (Justicia gendarussa Burm f.), que é conhecida por quebrar feitiço, desfazer "macumba", abrir caminhos, deixar para trás a negatividade, atuando como descarrego (Pagnocca, 2017). Os nomes populares das plantas geralmente estão relacionados à sua utilização. Nas espécies utilizadas em ritos religiosos, estes nomes foram resgatados com a implantação das religiões de matriz-africana no Brasil, sendo utilizados nomes de santos, ações curativas ou, até mesmo, devido à morfologia externa.

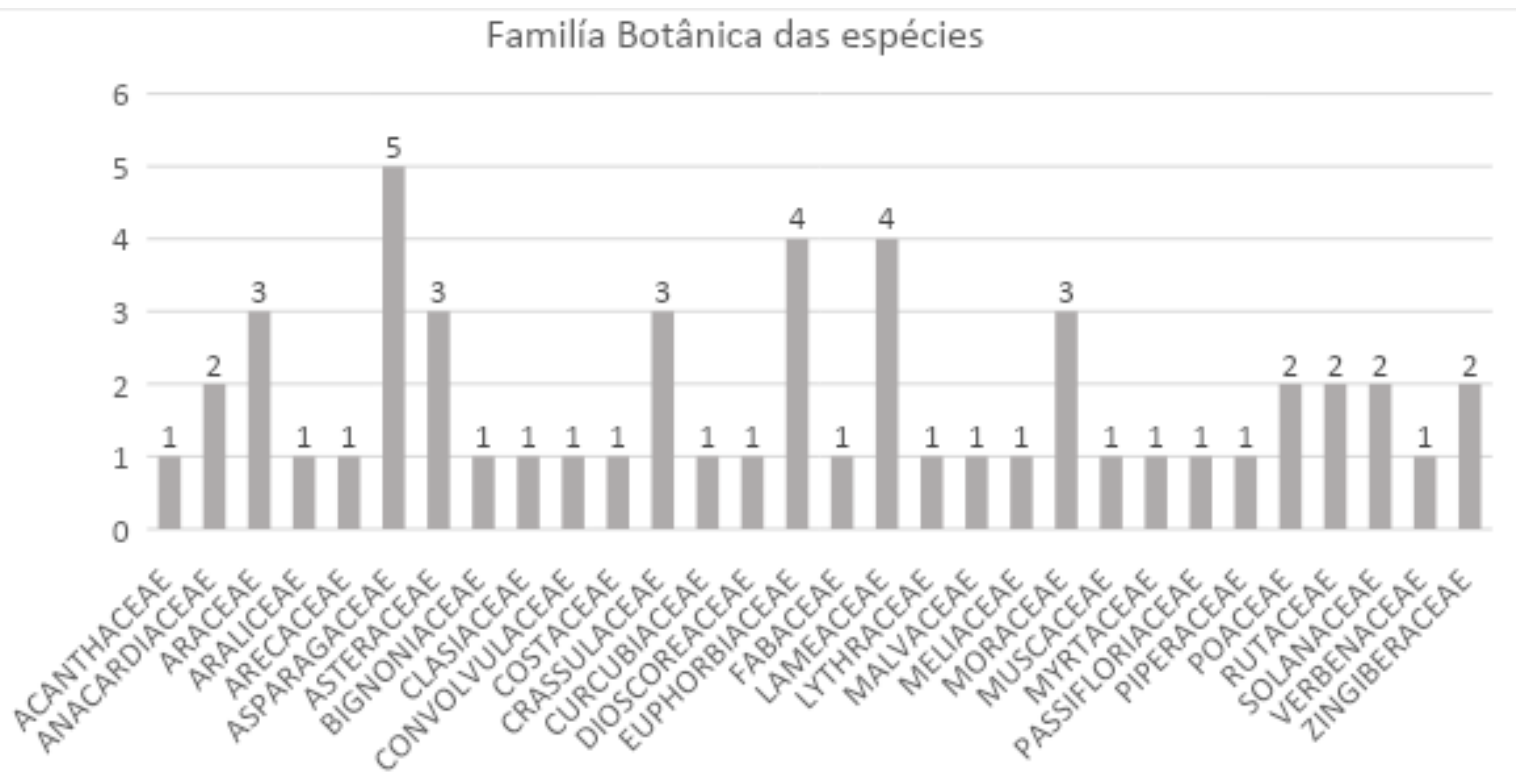

Figura 2. Recrutamento das famílias botânicas presentes no quintal do terreiro ILé Àse Tobi Babá Olorigbin, Ituiutaba, Minas Gerais.

De maneira geral, as plantas tóxicas apresentam estrutura e aparência expressivas, alertando para o cuidado. Podemos observar isto em comigo-ninguém-pode, Dieffenbachia amoena Bull, cujas folhas apresentam manchas brancas sobre a cor verde insinuando cuidado. É uma planta tóxica se consumida, entretanto, popularmente é usada na proteção contra energias negativas. As folhas que exibem espinhos, manchas e outros sinais de perigo são utilizadas em banhos quentes na Umbanda por 
serem consideradas plantas fortes, acreditando-se que elas ajudam a sacudir a vida, agitar e fornecer uma carga vital a pessoas desmotivadas e sem expectativas (Camargo, 2014).

Os resultados apresentados neste trabalho indicam que a capacidade das plantas de curar enfermidades está interligada com as crenças espirituais. Algumas plantas demonstram este aspecto, como o uso de folhas da alface-d'água (Pistia stratiotes L.) como banho, pois no meio religioso esta planta é usada para enfermidades da visão, promovendo limpeza nos olhos e para iniciar a mediunidade. Já na medicina popular, ela também é usada para curar males dos olhos, como conjuntivite, alergias e irritações (Medeiros et al., 2004). Assim, é possível observar uma relação na utilização da mesma espécie na medicina popular e em ritos religiosos, indicada para o tratamento de enfermidades oftálmicas.

A planta utilizada na forma de banho de descarrego na Umbanda é o boldo (Plectranthus ornatos Cool), uma espécie que apresenta grande capacidade de limpeza energética, conseguindo eliminar energias negativas acumuladas nas pessoas. Porém, na medicina popular, o boldo também tem a finalidade de limpeza do corpo, sendo utilizado principalmente em enfermidades relacionadas ao bom funcionamento do estômago, intestino e fígado, atuando, assim, na eliminação de impurezas do corpo (Santos; Almeida, 2016).

Outras plantas que apresentam capacidade de limpeza corporal são espada-de-são-jorge (Sansevieria trifasciata Prain), espada-de-santa-bárbara (Sansevieria zeylanica Willd) e lança-de-sãojorge (Sansevieria cylindrica Bojer), que servem para espantar energias negativas das pessoas e de locais (Pagnocca, 2017). Segundo os entrevistados, estas plantas, quando utilizadas como ornamentais, têm capacidade de purificar o ambiente, pois absorvem gases poluentes e eliminam oxigênio, indicando que o mecanismo de limpeza é uma relação do efeito da planta na atmosfera associada às crenças dos participantes, promovendo um resultado benéfico.

Com a análise nas respostas dos participantes e os conhecimentos empíricos destes, foi possível observar que o abébé (Polyscias scutellaria Burm f.) é uma planta com capacidade de atuar no aumento da autoestima da pessoa que faz o uso através do banho; além disso, promove ampla visão para enxergar as coisas felizes e alegres da vida, substituindo a sensação de tristeza e melhorando a qualidade de vida. O sacerdote do terreiro diz que esta planta atua no comportamento humano.

Os conhecimentos religiosos do babaorixá indicam que diversas plantas apresentam ações curativas, outras são utilizadas na decoração, como flores, sementes e folhas, promovendo, assim, o bem-estar, resultante da harmonização do ambiente, não apresentando cientificamente ação medicinal propriamente dita. Vale ressaltar que até as folhas que caem no chão do terreiro são utilizadas como incenso nas giras. Essas folhas, para a religião, recebem carinho, atenção, afeto e amor, e estes sentimentos criados sobre a planta se tornam parte das folhas. Assim, quando queimadas, elas eliminam essas energias positivas. Apesar de a fé ser o mecanismo que potencializa os princípios ativos das plantas utilizadas na religião, as espécies vegetais atuam como um intermédio para que a fé atue sobre a capacidade de cura da planta.

Através da análise dos dados obtidos com o formulário, foi possível observar diferença na idade entre os praticantes da religião: o integrante mais novo apresenta 20 anos de idade e o mais velho, 62 anos. Ao total, foram 11 participantes mulheres e 9 homens; todos que praticam a religião no terreiro Axé Olorigbin são moradores do município de Ituiutaba, Minas Gerais. Além disso, houve apenas uma pessoa que respondeu nunca ter usado planta para fins medicinais, enquanto outras 19 descreveram que utilizam plantas para fins de curar doenças do corpo e espírito.

Foi possível observar também que 33,8\% dos participantes usam as plantas na forma de banhos, $22,58 \%$ usam para benzedura, 20,97\% fazem uso através de chás, $12,9 \%$ usam as plantas para oferendas e 9,7\% utilizam as plantas externamente. Segundo Araújo (2014), que realizou um estudo de plantas utilizadas em ritos religiosos de matriz africana na comunidade de Campina Grande, PB, a utilização de chás foi majoritária, seguida de banhos. Assim é possível sugerir que o uso de plantas para banhos nos terreiros é bastante comum. A justificativa em relação aos banhos serem mais citados é devido à facilidade de manuseio e rápida ação terapêutica, sendo a técnica que os médiuns mais recomendam aos praticantes para obter as ações das plantas.

Em relação a frequências, número de vezes que uma planta foi citada, foi possível observar que das 53 espécies citadas, listadas no Anexo 1, apenas 12 delas foram citadas mais de uma vez, a saber: barbatimão e hortelã, citadas duas vezes; comigo-ninguém-pode e espada-de-são-jorge, três vezes; acoco, capim-cidreira e peregum, quatro vezes; guiné, cinco vezes; arnica, seis vezes; manjericão, oito vezes; e arruda e boldo com maior número de citações, treze vezes. As demais espécies apresentaram 
apenas uma única citação. Tanto a arruda quanto o boldo são utilizados na forma de banhos como descarrego.

Por fim, o uso de plantas em rituais de cura em terreiros de Umbanda e Candomblé por religiosos é uma prática cultural e bastante expressiva no Brasil. O conhecimento do babalorixá, associado às propriedades das plantas e à fé dos participantes, cria um universo místico no processo de cura.

\section{CONCLUSÕES}

As plantas utilizadas para fins medicinais descritas neste trabalho estão presentes na cura de males dos frequentadores dos terreiros, utilizadas tantos nos rituais quanto por indicação do sacerdote. A maior parte dos participantes respondeu que também fazem uso de plantas para fins medicinais. As espécies vegetais citadas mostram a diversidade existente no quintal do terreiro Axé Olorigbin. Com a catalogação destas espécies, foi possível identificar e compreender sobre a ação terapêutica e religiosa.

Foi observado também que as plantas podem atuar como intermédio da fé elaborada sobre as plantas, a qual pode estabelecer a eficiência do princípio de cura das plantas para potencializar seus efeitos e atuar sobre as enfermidades. Os resultados fornecidos nos formulários possibilitaram compreender sobre quais foram as mudanças depois dos participantes terem sido iniciados na religião, observando-se que a religião concede uma transformação da vida dos praticantes, tais como qualidade de vida, evolução espiritual, mental e física.

\section{REFERÊNCIAS}

ANGIOSPERM PHYLOGENY GROUP (APG). An update of the Angiosperm Phylogeny Group classification for the orders and families of flowering plants: APG IV. Botanical Journal of the Linnean Society, v. 81, p. 1-20, 2016.

ARAUJO, W. Através da terra: estudo de plantas utilizadas em rituais de cura por participantes de cultos religiosos de matriz africana em Campina Grande - PB. 2014. 78 f. Faculdade de História, Universidade Estadual da Paraíba, Paraíba, 2014.

CAMARGO, M.T.L.A. As plantas medicinais e o sagrado: a etnofarmacobotânica em uma revisão historiográfica da medicina popular no Brasil. 1. ed. São Paulo: Ícone, 2014.

CAMARGO, M.T.L. Plantas medicinais e de rituais afro-brasileiros. São Paulo: ALMED, 1988.

CASCUDO, L.C. Literatura oral no Brasil. Rio de Janeiro: José Olympio, 1978.

FERREIRA, M.F. Cosmologia do candomblé. Trabalho pedagógico, p. 1-19, 2019.

FIASCHI, P. Araliaceae In: Jardim Botânico do Rio de Janeiro, 2015. Disponível em: http://floradobrasil.jbrj.gov.br/jabot/floradobrasil/FB80524. Acesso em: 31 de ago. 2018.

HOLMGREN, P.K.; HOLMGREN, N.H.; BARNETT, L.C. Index Herbariorum. Part I: The Herbaria of the world. 8. ed. New York: International Association for Plant Taxonomy / New York Botanical Garden, 1990.

IBGE. Censo demográfico 2010: sinopse preliminar. Disponível em: https://cidades.ibge.gov.br/brasil/mg/ituiutaba/panorama. Acesso em: 24 jan 2019.

PREFEITURA DO MUNICÍPIO DE ITUIUTABA. Disponível em: https://www.ituiutaba.mg.gov.br/t/dadospopulacionais. Acesso em: 24 jan 2019.

MEDEIROS, M.F.T. et al. Plantas medicinais e seus usos pelos sitiantes da Reserva Rio das Pedras, Mangaratiba, RJ, Brasil. Acta bot. Bras, v. 18, n. 2, p. 391-399, 2004.

NEGRELLE, R.R.B.; FORNAZZARI, K.R.C. Estudo etnobotânico em duas comunidades rurais (Limeira e Ribeirão Grande) de Guaratuba (Paraná, Brasil). Revista Brasileira de Plantas Medicinais, v. 9, n. 2. p. 36-54, 2007.

PAGNOCCA, T.S. Uso de plantas terapêuticas em religiões afro-brasileiras na ilha de Santa Catarina. 2017. 107 f. Dissertação (Mestrado) - Universidade Federal de Santa Catarina, Florianópolis, 2017.

PIRES, M. V. et al. Etnobotânica de terreiros de candomblé nos municípios de Ilhéus e Itabuna, Bahia, Brasil.

Revista Brasileira de Biociências, Porto Alegre, v. 7, n. 1, p.1-8, 2009.

PORTUGUEZ, A.P. Plantando axé: do lugar sagrado ao território da militância e da resistência cultural. 1.

ed. Ituiutaba, MG: Barlavento, 2016.

PORTUGUEZ, A.P. Espaço e cultura na religiosidade afro-brasileira. 1. ed. Ituiutaba: Barlavento, 2015.

SANTOS, J.S.; ALMEIDA, C.C.O.F. Plantas medicinais fitoterapia: uma ciência em expansão. Brasília: Editora IFB, 2016.

SCHILLING, A.C.; BATISTA, J.L.F. Curva de acumulação de espécies e suficiência amostral em florestas tropicais. Revista Brasileira de Botânica, Santa Maria, v. 31, n. 1, p. 179-187, 2008.

SILVA, V.G. Candomblé e Umbanda: caminho de devoção brasileira. 3. ed. São Paulo: Selo Negro Edições, 2005. 
Anexo 1. Espécies utilizadas para fins ritualísticos no Centro Religioso Axé Olorigbin do município de Ituiutaba, Minas Gerais.

\begin{tabular}{llll}
\hline FAMILIA/Nome científico & Nome Religioso & Nome Popular & Uso Religioso \\
\hline $\begin{array}{l}\text { ACANTHACEAE } \\
\text { Justicia gendarussa } \text { (Burm. f.) }\end{array}$ & vence-demanda, tira-teima & $\begin{array}{l}\text { abre-caminho, quebra- } \\
\text { tudo, vende-tudo }\end{array}$ & $\begin{array}{l}\text { banho abre caminhos e quebra } \\
\text { feitiços }\end{array}$ \\
$\begin{array}{l}\text { ANACARDIACEAE } \\
\text { Spondias dulcis (G. Forst.) }\end{array}$ & cajazeira & cajá-manga & $\begin{array}{l}\text { árvore da ancestralidade feminina, } \\
\text { fruto não pode ser comido, planta } \\
\text { sagrada }\end{array}$ \\
Mangifera indica (L.) & mangueira & mangueira & $\begin{array}{l}\text { Banho da fertilidade ou nas giras } \\
\text { para descarregar energias negativas }\end{array}$
\end{tabular}

\section{ARACEAE}

Colocasia esculenta $(\mathrm{L}$.$) \quad inhame$

Schott

Dieffenbachia amoena (Bull) comigo-ninguém-pode

Pistia stratiotes (L.)

ojuoro, erva-de-santa-luzia

Polyscias scutellaria (Burm. abébé

f.)

\section{ARECACEAE}

Elaeis guineensis (Jacq.) dendezeiro

\section{ASPARAGACEAE}

Sansevieria cylindrica (Bojer) lança-de-são-jorge

Sansevieria trifasciata (Prain) espada-de-são-jorge verde

Sansevieria zeylanica (willd.) espada-de-santa-barbara, espada-de-carijó, espada-deoxossi

Dracaena deremensis Engl. peregum-verde

Dracaena fragrans (L.) Ker Peregum, carijó-amarelo Gawl.

\section{ASTERACEAE}

Acmella oleracea (L.) R.K. capeba, oripepé, jambú Jansen

Elephantopus mollis (Kunth) língua-de-vaca inhame-coco, inhame- folhas para servir oferendas dos-açores, taioba

comigo-ninguém-pode banho quente, ativa vida, abre caminhos ou limpeza espiritual banho auxilia na visão, desenvolver mediunidade.

erva- capitão, banho ligado a autoestima, visão acaricioba, arália-de- para as coisas felizes e retirar balfour, acariroba tristezas

dendezeiro, palmeira- folhas utilizadas para fazer franjas de-óleo-africana, de Mariô; raízes, galhos e frutos palmeira-dendém, são utilizados para decoração e palma-de-guiné oferendas

lança-de-são-jorge

banho utilizado para limpezas corporais e locais, espantar energias negativas

espada-de-são-jorge, banho utilizado para limpezas rabo-de-lagarto

corporais e locais, espantar energias negativas

espada-de-santa- $\quad$ banho utilizada para limpezas

barbara

dracena, peregumcorporais e locais, espantar energias negativas. banho que auxilia na manifestação dos orixás, leva ao transe, atrair sorte

peregum-amarelo banho para limpeza, proteção e sacudimento

banho frio para acalmar cabeça

jambú, jabuaçu, ervamaluca, agrião do quente norte, agrião-do-pará erva-grossa, fumobanho quente, auxilia na bravo, erva-decolégio, suçuaia purificação e fortificará em cumprir as obrigações 


\begin{tabular}{|c|c|c|c|}
\hline FAMILIA/Nome científico & Nome Religioso & Nome Popular & Uso Religioso \\
\hline Solidago chilensis (Meyen) & arnica & $\begin{array}{l}\text { espiga-de-outro, } \\
\text { arnica-do-campo, } \\
\text { arnica-silvestre }\end{array}$ & banho para limpeza corporal \\
\hline \multicolumn{4}{|l|}{ BIGNONIACEAE } \\
\hline $\begin{array}{l}\text { Newbouldia laevis (P. Beauv.) } \\
\text { Seem. ex Bureau. }\end{array}$ & acoco-africano & $\begin{array}{l}\text { acoco, akóko, } \\
\text { newbouldia }\end{array}$ & $\begin{array}{l}\text { banho para prosperidade de } \\
\text { dinheiro e filhos (multiplicação) }\end{array}$ \\
\hline \multicolumn{4}{|l|}{ CLUSIACEAE } \\
\hline Garcinia kola (Heckel) & Orobô & orogbô, orobó & $\begin{array}{l}\text { pedir permissão para os orixás para } \\
\text { realizarem rituais }\end{array}$ \\
\hline \multicolumn{4}{|l|}{ CONVOLVULACEAE } \\
\hline $\begin{array}{l}\text { Ipomoea sect. Batatas } \\
\text { (Choisy) Griseb }\end{array}$ & eue-caxuman & batata-doce & $\begin{array}{l}\text { banho atuará na fertilidade e adoçar } \\
\text { corações amargos }\end{array}$ \\
\hline \multicolumn{4}{|l|}{ COSTACEAE } \\
\hline Costus spicatus (Jacq.) Sw. & $\begin{array}{l}\text { canela-de-macaco, ewé } \\
\text { tètèrègún e pèrègún. }\end{array}$ & $\begin{array}{l}\text { cana-de-macaco, } \\
\text { cana-do-brejo }\end{array}$ & $\begin{array}{l}\text { banho para limpeza, acalmar e } \\
\text { tranquilizar }\end{array}$ \\
\hline \multicolumn{4}{|l|}{ CRASSULACEAE } \\
\hline $\begin{array}{l}\text { Bryophyllum Pinnatum (Lam.) } \\
\text { Kurz }\end{array}$ & fortuna & $\begin{array}{l}\text { milagre-de-são- } \\
\text { joaquim, saião, folha } \\
\text { grossa, fortuna }\end{array}$ & $\begin{array}{l}\text { banho para atrair prosperidade, } \\
\text { calmante, dificuldade na } \\
\text { concentração e manter a cabeça nos } \\
\text { estudos }\end{array}$ \\
\hline $\begin{array}{l}\text { Kalanchoe brasiliensis } \\
\text { (Cambess) }\end{array}$ & Saião & $\begin{array}{l}\text { calanchoê, flor-da- } \\
\text { fortuna, erva-da-costa }\end{array}$ & $\begin{array}{l}\text { banho para a visão, esclarecer } \\
\text { melhor os olhos, utilizados para } \\
\text { vendar os olhos das oferendas para } \\
\text { não ver a morte e banhar os búzios. }\end{array}$ \\
\hline Kalanchoe laetivirens Desc. & língua-de-exu & $\begin{array}{l}\text { aranto, mãe-de- } \\
\text { milhares, mãe-de-mil- } \\
\text { filhos }\end{array}$ & $\begin{array}{l}\text { banho atua para aumentar } \\
\text { comunicação }\end{array}$ \\
\hline \multicolumn{4}{|l|}{ CURCUBIACEAE } \\
\hline Luffa aegyptiaca (L.) & bucha-vegetal & $\begin{array}{l}\text { bucha, bucha-dos- } \\
\text { paulistas, bucha-de- } \\
\text { pescador, esfregão }\end{array}$ & $\begin{array}{l}\text { banho de folhas para limpeza } \\
\text { espiritual }\end{array}$ \\
\hline \multicolumn{4}{|l|}{ DIOSCOREACEAE } \\
\hline Dioscorea bulbifera (L.) & inhame-cará & $\begin{array}{l}\text { cará-do-ar, inhame- } \\
\text { do-ar, cará-moela }\end{array}$ & $\begin{array}{l}\text { servir oferendas aos orixás (folhas e } \\
\text { tubérculo) }\end{array}$ \\
\hline \multicolumn{4}{|l|}{ EUPHORBIACEAE } \\
\hline Jatropha gossypiifolia (L.) & pinhão-roxo & $\begin{array}{l}\text { pinhão-de-purga, } \\
\text { pinhão-paraguaio, } \\
\text { pinhão-bravo }\end{array}$ & $\begin{array}{l}\text { banho para crianças que crescem } \\
\text { com amarelão. }\end{array}$ \\
\hline \multicolumn{4}{|l|}{ EUPHORBIACEAE } \\
\hline Ricinus communis (L.) & mamona & rícino, mamona & $\begin{array}{l}\text { banho de limpeza, folhas para } \\
\text { servir oferendas e decorações }\end{array}$ \\
\hline Ricinus sanguineus (Groenl.) & mamona-roxa & mamona, carrapateira & $\begin{array}{l}\text { limpeza de energias negativas, } \\
\text { folhas para servir oferendas e fruto } \\
\text { decoração }\end{array}$ \\
\hline Ruta graveolens( L.) & arruda & $\begin{array}{l}\text { arruda-fedida, arruda- } \\
\text { doméstica, arruda- } \\
\text { dos-jardins }\end{array}$ & benzedura \\
\hline \multicolumn{4}{|l|}{ FABACEAE } \\
\hline $\begin{array}{l}\text { Tetrapleura tetráptera } \\
\text { (Schumach. E Thonn) }\end{array}$ & aridã, aridan & fava-de-aridan & $\begin{array}{l}\text { banho para atrair boa sorte e } \\
\text { proteção de feitiços }\end{array}$ \\
\hline \multicolumn{4}{|l|}{ LAMIACEAE } \\
\hline Plectranthus ornatus (cood) & boldo-miúdo & $\begin{array}{l}\text { boldo-gambá, boldo- } \\
\text { rasteiro }\end{array}$ & $\begin{array}{l}\text { banho frio, auxilia no relançamento } \\
\text { e tranquilizante }\end{array}$ \\
\hline
\end{tabular}




\begin{tabular}{|c|c|c|c|}
\hline FAMILIA/Nome científico & Nome Religioso & Nome Popular & Uso Religioso \\
\hline Ocimum basilicum (L.) & alfavaca & $\begin{array}{l}\text { alfavaca, alfavaca-de- } \\
\text { vaqueiro }\end{array}$ & $\begin{array}{l}\text { banho para limpeza corporal, } \\
\text { auxilia na filtragem do sangue }\end{array}$ \\
\hline Ocimum thyrsiflorum (L.) & manjericão & $\begin{array}{l}\text { manjericão, alfavaca, } \\
\text { alfavacão }\end{array}$ & $\begin{array}{l}\text { banho quente para retirar } \\
\text { negatividades, energia ruins e } \\
\text { fornecer disposição e ânimo }\end{array}$ \\
\hline $\begin{array}{l}\text { Plectranthus amboinicus } \\
\text { (Lour.) spreng }\end{array}$ & boldo-graúdo & $\begin{array}{l}\text { boldo-brasileiro, } \\
\text { falso-boldo, hortelã- } \\
\text { graúda }\end{array}$ & \\
\hline \multicolumn{4}{|l|}{ LYTHRACEAE } \\
\hline Punica granatum (L.) & romã & $\begin{array}{l}\text { romãnzeiro, romeira, } \\
\text { granada, miligrana }\end{array}$ & $\begin{array}{l}\text { banho quente abrir os olhos para si } \\
\text { mesmo, união de amigos e } \\
\text { familiares }\end{array}$ \\
\hline \multicolumn{4}{|l|}{ MALVACEAE } \\
\hline Cola acuminata (P.Beauv) & obi, noz-de-cola & café-do-fundão, cola & $\begin{array}{l}\text { banho utilizado para permissão dos } \\
\text { orixás para realizarem rituais }\end{array}$ \\
\hline \multicolumn{4}{|l|}{ MELIACEAE } \\
\hline Melia azedarach (L.) & para-raio & $\begin{array}{l}\text { santa-bárbara, árvore- } \\
\text { do-paraíso, } \\
\text { cinamomo, } \\
\text { amargoseira, jasmim- } \\
\text { de-calena }\end{array}$ & limpeza do ambiente \\
\hline \multicolumn{4}{|l|}{ MORACEAE } \\
\hline $\begin{array}{l}\text { Artocarpus heterophyllus } \\
\text { (Lan.) }\end{array}$ & jaqueira, apaoka & jaca-mole, jaca-dura & $\begin{array}{l}\text { banho relacionado ancestralidade } \\
\text { feminina, utiliza para consagrar aos } \\
\text { cultos a ìyàmi }\end{array}$ \\
\hline Ficus gomelleira (Kunth) & gameleira-branca & $\begin{array}{l}\text { cerejeira, figueira- } \\
\text { brava, gameleira-de- } \\
\text { purga }\end{array}$ & $\begin{array}{l}\text { árvore sagrada, responsável por } \\
\text { esta árvore que os orixás descem a } \\
\text { terra }\end{array}$ \\
\hline Morus nigra (L.) & amora & $\begin{array}{l}\text { amoreira-negra, } \\
\text { amora, amora-negra }\end{array}$ & $\begin{array}{l}\text { banho ligado a rituais em conexão } \\
\text { com os ancestrais }\end{array}$ \\
\hline \multicolumn{4}{|l|}{ MUSACEAE } \\
\hline Musa sp. & bananeira & banana-nanica & $\begin{array}{l}\text { embrulhar e dar forma aos } \\
\text { alimentos }\end{array}$ \\
\hline \multicolumn{4}{|l|}{ MYRTACEAE } \\
\hline Psidium guajava (L.) & goiabeira & $\begin{array}{l}\text { goiaba, araçá-goiaba, } \\
\text { guaiaba, araçá-das- } \\
\text { almas }\end{array}$ & $\begin{array}{l}\text { utiliza como aquidavi baqueta para } \\
\text { instrumento }\end{array}$ \\
\hline \multicolumn{4}{|l|}{ PASSIFLORIACEAE } \\
\hline Passiflora edulis (Sims) & maracujá & maracujazeiro & $\begin{array}{l}\text { banho de folha para iniciação do } \\
\text { orixá, o fruto é utilizado em ritos } \\
\text { para depressão e tristezas ligadas ao } \\
\text { amor }\end{array}$ \\
\hline \multicolumn{4}{|l|}{ PIPERACEAE } \\
\hline Peperomia pellucida (L.) & oriri & $\begin{array}{l}\text { erva-de-jabuti, } \\
\text { alfavaquinha-de- } \\
\text { cobra, oriri }\end{array}$ & auxilia na visão e calmante \\
\hline \multicolumn{4}{|l|}{ POACEAE } \\
\hline $\begin{array}{l}\text { Cymbopogon citratus (DC.) } \\
\text { Stapf } \\
\text { Zea mays (L.) }\end{array}$ & $\begin{array}{l}\text { capim-cidreira } \\
\text { milho, abadô }\end{array}$ & $\begin{array}{l}\text { capim-limão, capim- } \\
\text { santo, erva-príncipe } \\
\text { milho }\end{array}$ & $\begin{array}{l}\text { banho calmante, relaxante e trazer } \\
\text { equilíbrio } \\
\text { grãos e cabelos são utilizados para } \\
\text { atrair prosperidade }\end{array}$ \\
\hline \multicolumn{4}{|l|}{ RUTACEAE } \\
\hline Murraya paniculata (L.) & cafezeira, café & $\begin{array}{l}\text { falsa-murta, murta-de- } \\
\text { cheiro, dama-da-noite }\end{array}$ & $\begin{array}{l}\text { decorações em rituais e aquidavi } \\
\text { (instrumento) }\end{array}$ \\
\hline
\end{tabular}




\begin{tabular}{|c|c|c|c|}
\hline FAMILIA/Nome científico & Nome Religioso & Nome Popular & Uso Religioso \\
\hline $\begin{array}{l}\text { Pilocarpus microphyllus } \\
\text { (Stapf ex Wardlew.) }\end{array}$ & jaborandi & $\begin{array}{l}\text { jabrandi-do- } \\
\text { maranhão, jaborandi- } \\
\text { legítimo, jaborandi }\end{array}$ & banho quente para dar ânimo \\
\hline \multicolumn{4}{|l|}{ SOLANACEAE } \\
\hline $\begin{array}{l}\text { Solanum aculeatissimum } \\
\text { (Jacq.) }\end{array}$ & espinheira & $\begin{array}{l}\text { arrebenta cavalo, joá, } \\
\text { joazeiro, joá-de- } \\
\text { espinho }\end{array}$ & $\begin{array}{l}\text { planta muito quente funções para } \\
\text { exu, fundamentar o orixá, utilizadas } \\
\text { para alimentos, decoração }\end{array}$ \\
\hline Solanum cernuum (Vell.) & panaceia & $\begin{array}{l}\text { barba-de-bode, } \\
\text { panaceia, velame }\end{array}$ & banho para caxumba e testículo. \\
\hline \multicolumn{4}{|l|}{ VERBENACEAE } \\
\hline $\begin{array}{l}\text { Aloysia gratissima (Gillies \& } \\
\text { Hook.) Tronc. }\end{array}$ & alfazema-brasileira, & $\begin{array}{l}\text { erva-santa, alfazema- } \\
\text { cabocla, erva-da- } \\
\text { graça, erva-de-colónia }\end{array}$ & banho para atrair energias positivas. \\
\hline \multicolumn{4}{|l|}{ ZINGIBERACEAE } \\
\hline $\begin{array}{l}\text { Alpinia speciosa (J.C. Wendl.) } \\
\text { K. Schum. }\end{array}$ & colônia & $\begin{array}{l}\text { flor-de-colônia, } \\
\text { gengibre-concha, } \\
\text { gengibre-casca, } \\
\text { macacá }\end{array}$ & banho calmante e tranquilizante \\
\hline Zingiber officinale (Roscoe.) & gengibre & $\begin{array}{l}\text { gengibre, } \\
\text { mangarataia, } \\
\text { gengibre, gengivre }\end{array}$ & $\begin{array}{l}\text { bebida sagrada dos orixás chamada } \\
\text { aruá, atrair prosperidade e saúde }\end{array}$ \\
\hline
\end{tabular}

